\title{
Changes in smoking behavior among victims after the great East Japan earthquake and tsunami
}

Yoneatsu Osaki ${ }^{*} \mathbb{D}$, Hitoshi Maesato², Ruriko Minobe², Aya Kinjo', Yuki Kuwabara', Aya Imamoto ${ }^{3}$, Yoshinori Myoga', Sachio Matsushita ${ }^{2}$ and Susumu Higuchi ${ }^{2}$

\begin{abstract}
Background: In areas affected by the tsunami of the great East Japan Earthquake, smoking behavior may have deteriorated due to high stress and drastic changes in living environment. Surveys were conducted to reveal changes in smoking behaviors among victims.

Methods: A population-based random-sample home-visit interview survey of victims in Iwate and Miyagi Prefectures affected by the tsunami disaster was conducted in $2012(n=1978)$, while a population-based nationwide survey was conducted in 2013 ( $n=1082$ ). A panel survey in 2014 was conducted with respondents of the 2012 survey $(n=930)$. Multiple logistic regression analysis was performed to reveal factors related to smoking status after the disaster.

Results: There was high smoking prevalence of both sexes in the tsunami disaster area (current smoking rate in coastal area, $50.0 \%$ for male, 21.4\% for female; inland area, 34.7\% for male, $7.6 \%$ for female). Low prevalence of male quitters was observed (quitter rate in coastal area, 20.8\% for male, 8.0\% for female; inland area, 23.4\% for male, 5.5\% for female). The prevalence of nicotine-dependent people assessed by FTND (Fagerström Test for Nicotine Dependence) in the coastal area was also higher than in the inland area or other areas of Japan. Smoking behavior among victims worsened after the disaster and did not improve 3 years from the disaster. Post-disaster factors related to smoking were living in coastal area, complete destruction of house, and living in temporary housing.

Conclusions: Smoking prevalence and the level of nicotine dependence of tsunami victims were still high even 3 years after the disaster. It is important to emphasize measures for smoking control in the disaster areas for an extended time period.
\end{abstract}

Keywords: Natural disaster, Smoking, Tsunami, Nicotine dependence, Great East Japan earthquake

\footnotetext{
* Correspondence: yoneatsu@tottori-u.ac.jp

'Division of Environmental and Preventive Medicine, Department of Social

Medicine, Faculty of Medicine, Tottori University, 86 Nishi-cho, Yonago,

Tottori 683-8503, Japan

Full list of author information is available at the end of the article
}

(c) The Author(s). 2020 Open Access This article is licensed under a Creative Commons Attribution 4.0 International License, which permits use, sharing, adaptation, distribution and reproduction in any medium or format, as long as you give appropriate credit to the original author(s) and the source, provide a link to the Creative Commons licence, and indicate if changes were made. The images or other third party material in this article are included in the article's Creative Commons licence, unless indicated otherwise in a credit line to the material. If material is not included in the article's Creative Commons licence and your intended use is not permitted by statutory regulation or exceeds the permitted use, you will need to obtain permission directly from the copyright holder. To view a copy of this licence, visit http://creativecommons.org/licenses/by/4.0/. The Creative Commons Public Domain Dedication waiver (http://creativecommons.org/publicdomain/zero/1.0/) applies to the data made available in this article, unless otherwise stated in a credit line to the data. 


\section{Introduction}

The great East Japan Earthquake was a magnitude 9.0$9.1(\mathrm{Mw})$ undersea megathrust earthquake off the coast of Japan that occurred on March 11, 2011. It was the most powerful earthquake ever recorded in Japan. The earthquake triggered powerful tsunami waves that may have reached heights of up to $40.5 \mathrm{~m}$ (133 ft), and which, in the Sendai area, traveled up to $10 \mathrm{~km}$ inland. The tsunami swept the Japanese mainland and killed many people, mainly through drowning, though blunt trauma also caused many deaths. The latest report from the Japanese National Police Agency confirmed 15,897 deaths, 6157 injured cases, and 2533 missing cases across twenty prefectures (as of March 8,2019 ) [1], and the number of refugees was approximately 347 thousand at its peak in 2012. A 2019 report indicated that approximately 52,000 people were still living away from their homes in temporary housing [2]. The National Police Agency report listed 121,990 buildings as "totally collapsed," with a further 282,900 buildings "half collapsed" and another 730,044 buildings "partially damaged" [1]. The earthquake and tsunami also caused extensive, severe infrastructural damage in north-eastern Japan. In the 65 years since the end of World War II, this has been the toughest crisis faced by Japan.

In the disaster area, many people were forced to live long term as evacuees in environments different from those of conventional life, such as temporary housing or rental houses. How health-related lifestyle changed after the disaster is important to understand in order to protect the health of the victims. Some reports have indicated that the smoking behavior of victims has changed after natural and human-made disasters: the September 11, 2001, attacks [3-5]; Hurricane Katrina, in 2005 [6, 7]; bushfires around Canberra, in 2003 [8]; and the Enschede fireworks disaster in the Netherlands, in 2000 [9]. However, there are few reports about smoking behavior after an earthquake or tsunami. Some articles on smoking behavior after a New Zealand earthquake have been published [10], and one article reported decreased smoking prevalence among victims in Fukushima Prefecture after the great East Japan Earthquake [11]. However, no article describing smoking behavior among victims in tsunami-damaged parts of Miyagi and Iwate Prefectures has been found. We conducted a survey to identify changes in smoking behavior of victims after the disaster in Miyagi and Iwate Prefectures. The current study hypothesis was that the smoking status of people in the tsunami-damaged area had worsened after the disaster and that had improved subsequently. The study provides findings that stress the importance of improvising measures for smoking control in disaster areas in the long term to reduce future health hazard.

\section{Materials and methods}

A population-based random-sample home-visit interview survey of victims in Iwate and Miyagi Prefectures affected by the tsunami disaster was conducted in 2012 $(n=1978)$. In order to compare with the results of the 2012 survey, we conducted a nationwide survey in 2013 except for the three affected prefectures using the same questionnaire $(n=1082)$. A panel survey in 2014 was conducted with respondents of the 2012 survey $(n=$ 930). The outline of this study was shown in Fig. 1.

\section{Participants}

Participants of the present survey were survivors living in the disaster area. This study includes an interview survey conducted in the disaster area in 2012, a panel survey in the disaster area 2 years later and a nationwide survey excluding the disaster area in 2013. The survey in the tsunami disaster area was conducted in the Iwate and Miyagi Prefectures. Fukushima Prefecture was excluded from the survey area, because conducting home visits to administer the interview survey was still difficult at that time, and many people were still living as refugees, distant from their registered addresses. A municipality that had a coastline at the boundary was defined as a coastal area. A municipality that did not have a coastline at the boundary was defined as an inland area. Sendai City of Miyagi Prefecture, which has a large population, defined a ward with coastline at the boundary as a coastal area and a ward without the coastline as an inland area.

\section{Procedures}

We randomly selected 1800 people from the coastal area and 1800 people from the inland area in the Iwate and Miyagi Prefectures using the resident resisters of local municipalities. Trained investigators requested them for their cooperation and visited participants who had consented to an interview. We entrusted a survey company called the Shin Joho Center to carry out the sample selections and home visit interview surveys. The survey company requested the sampling of residents to the municipalities, and the investigators visited municipal offices and randomly selected residents from the Basic Resident Register. Investigators were 49 well-trained employees of the survey company living in Miyagi and Iwate Prefectures.

The number of respondents was 1006 for the coastal area $(56 \%$ of response rate and $58 \%$ of actual response rate excluded by moving, address unknown, and longtime absent) and 972 for the inland area (54\% of response rate, $59 \%$ of actual response rate). The survey period was November to December 2012.

We then conducted a national survey on smoking behavior to compare with the findings from the disaster area; hence, the national survey excluded the three 
The 2012 target population in the disaster area (Iwate and Miyagi prefecture)

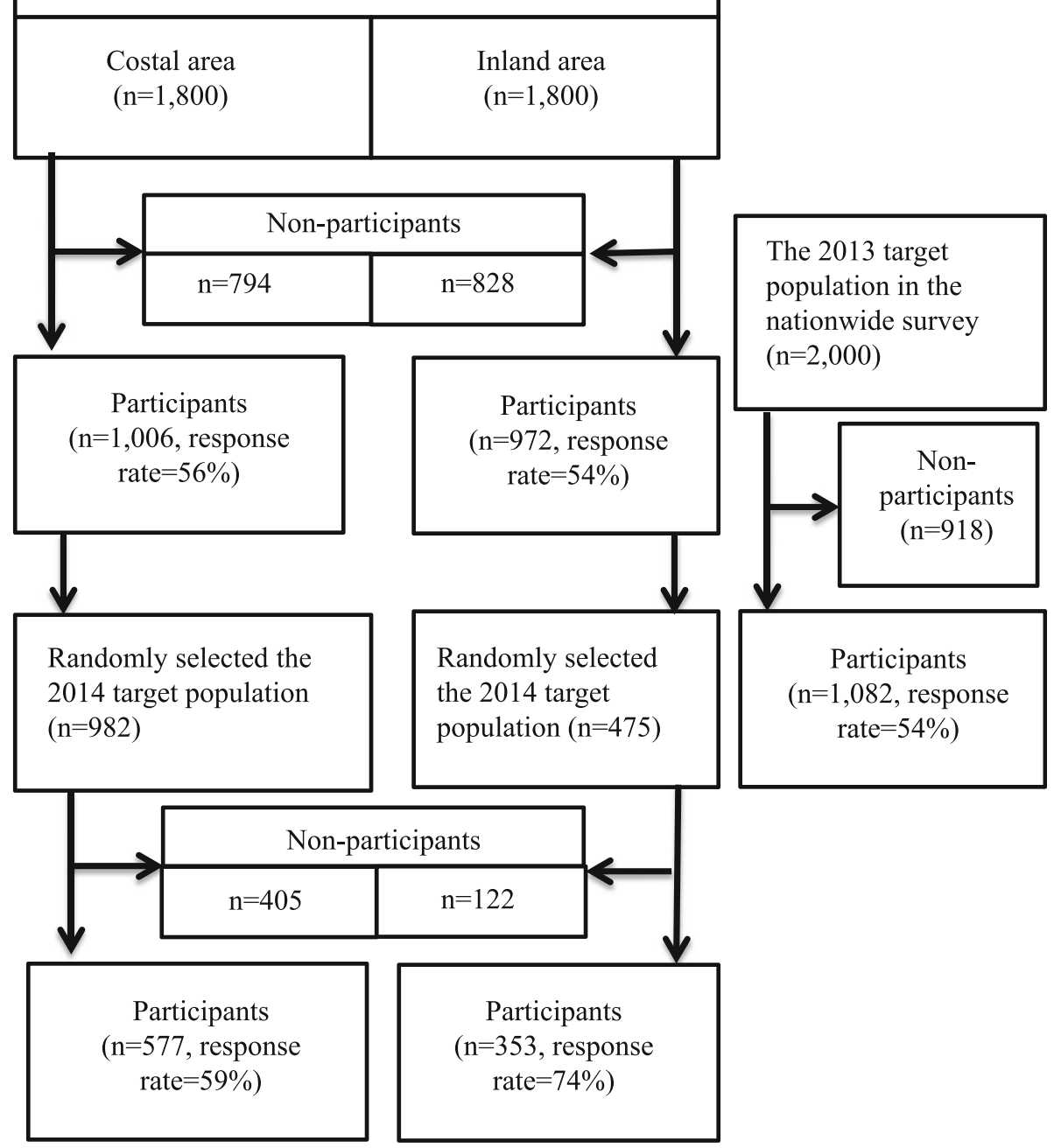

Fig. 1 Flow chart for this survey

disaster-hit prefectures (Iwate, Miyagi, and Fukushima). We randomly selected 2000 people by two-stage random sampling based on the points and the resident registers. We obtained answers from 1082 people (54\% of response rate, $59 \%$ of real response rate; including one incomplete questionnaire). The survey period was from November to December 2013. The content of the questionnaire was similar to that of the 2012 survey conducted in the disaster area. The 2014 survey was conducted with the respondents of the 2012 survey, though funding limitations meant only half as many participants in the inland area could be interviewed. Thus, 982 people from the coastal area and 475 people from the inland area (total of 1457) were asked to take the second survey, and 577 (59\% of response rate) and 353 people (74\% of response rate) agreed to do so (a total of
930 respondents). The survey period was from November to December 2014. Many respondents who were registered in the coastal area in the 2012 survey could not be contacted in 2014 survey: 199 people had moved to unknown places; 40 people were absent for a long time, and the addresses of 19 people were not exist out of 982 coastal samples. The actual response rate for the coastal area was $80 \%$, similar to the $84 \%$ for the inland area.

\section{Measures}

The survey covered current smoking status, nicotine dependence (FTND, Fagerström Test for Nicotine Dependence; TDS, Tobacco Dependence Screener) [12, 13], damage or challenges due to the situation during and after the tsunami and earthquake, and sociodemographic factors. Smoking status was classified into three groups 
(current smoker, ex-smoker, never smoker) according to the two questions: "Have you ever smoked a conventional cigarette more than 100?," and "Did you every day or sometimes smoke cigarettes for this one month?"

FTND scale contains six items that evaluate the quantity of cigarette consumption, the compulsion to use, and dependence. Questionnaires are as follows. (1) How soon after you wake up do you smoke your first cigarette? (2) Do you find it difficult to refrain from smoking in places where it is forbidden? (3) Which cigarette would you hate most to give up? (the first one in the morning or any other cigarette), (4) How many cigarettes per day do you smoke? (5) Do you smoke more frequently during the first hours after waking than during the rest of the day? (6) Do you smoke when you are so ill that you are in bed most of the day? For scoring of FTND, yes/no items are scored from 0 to 1 , and multiple-choice items are scored from 0 to 3 . The items are summed to yield a total score of $0-10$. The higher the total score, the more intense is the patient's physical dependence on nicotine.

The indexes used for the analyses were the mean of FTND, the proportion of persons with moderate or severe nicotine dependence (scores higher four points) as per FTND, the proportion of persons with severe nicotine dependence (more than seven points) as per FTND, the mean of TDS, and the proportion of person with nicotine dependence as per TDS (more than five points). Exacerbation of the smoking status in the panel survey is that never smokers or ex-smokers become current smokers, and improvement of the smoking status is that current smokers become ex-smokers. AUDIT (Alcohol Use Disorders Identification Test) was used as a screening test for alcoholism [14]. It is said that the cut-off point of AUDIT varies from country to country, and studies conducted in Japan have used more than 12 points for problem drinking and more than 15 points for alcohol dependence [15].

\section{Data analysis}

For statistical testing for means, the $t$ test was used for the analysis, and the paired $t$ test for the comparison of
2012 with 2014 results. For statistical testing for proportions, the chi-squared test was used to test the difference in proportion of 2012 and 2014. When the expectation numbers for chi-squared test are small, we used a Fisher's exact test. We conducted multiple logistic regression analysis using the variable increase method by the likelihood ratio. We conducted multivariable analysis with smoking status or dependence status as a dependent variable. The dependent variable was current smoking in 2012 or 2014, and independent variables were coast area/inland area, sex, age, years of education, marriage status, employment status, and damage due to the disaster (as of 2012 or 2014). Because the association between candidate factors was strong especially for damage due to the disaster, the statistical analysis to examine each factor was repeated using a statistical model including sex, age, and each candidate factor. We analyzed data with personal information removed, using SPSS Ver. 24 (IBM SPSS, Chicago, IL, USA).

\section{Results}

The current smoking rate in the coastal area affected by both the earthquake and the tsunami was $50.0 \%$ for male and $21.4 \%$ for female participants in 2012, higher than in the inland area affected by the earthquake only $(34.7 \%$ for male and $7.6 \%$ for female). Smoking prevalence in the coastal area was higher than that in the nationwide survey in 2013 (31.2\% for male and $10.6 \%$ for female) (Table 1).

The proportion of quitters in the coastal area in 2012 was $20.8 \%$ for male and $8.0 \%$ for female, whereas that in the inland area was $23.4 \%$ for male and $5.5 \%$ for female. These figures in coastal area were statistically similar to those in the inland area, and the figure for males in coastal area was statistically lower than the figure from a nationwide survey in 2013 (30.5\% for male and $7.7 \%$ for female).

The prevalence of people with nicotine dependence in the coastal area in 2012 according to the FTND test was $8.7 \%$ for severely dependent males and $29.4 \%$ for moderately dependent males and $2.8 \%$ for severely dependent

Table 1 Smoking status by area (disaster are in 2012, all Japan in 2013)

\begin{tabular}{|c|c|c|c|c|c|c|c|c|c|c|c|c|}
\hline \multirow[b]{2}{*}{ age group } & \multicolumn{4}{|c|}{ Coastal area (Iwate and Miyagi; $n=1,006$ ) } & \multicolumn{4}{|c|}{ Inland area (Iwate and Miyagi; $n=972$ ) } & \multicolumn{4}{|c|}{ All Japan $(n=1081)$} \\
\hline & $\begin{array}{r}\text { male }(n=4 \\
\text { current smoker }(\%)\end{array}$ & $\begin{array}{l}36) \\
\text { quitter (\%) }\end{array}$ & $\begin{array}{l}\text { female }(n=5 \\
\text { current }(\%)\end{array}$ & $\begin{array}{l}\text { 70) } \\
\text { quitter (\%) }\end{array}$ & $\begin{array}{l}\text { male }(n=426 \\
\text { current }(\%) q\end{array}$ & quitter (\%) & $\begin{array}{l}\text { female }(\mathrm{n}= \\
\text { current }(\%\end{array}$ & $\begin{array}{l}=546) \\
\text { quitter (\%) }\end{array}$ & $\begin{array}{l}\text { male }(n=493 \\
\text { current }(\%)\end{array}$ & q) & $\begin{array}{l}\text { female }(n=5 \\
\text { current }(\%)\end{array}$ & $\begin{array}{l}88) \\
\text { quitter (\%) }\end{array}$ \\
\hline $20-29$ & 47.1 & 11.8 & 34.5 & 13.8 & 37.5 & 6.3 & 12.0 & 10.0 & 25.6 & 0.0 & 17.2 & 4.7 \\
\hline $30-39$ & 60.0 & 8.0 & 34.5 & 15.5 & 44.4 & 20.4 & 18.5 & 6.2 & 39.2 & 21.6 & 9.7 & 15.1 \\
\hline $40-49$ & 64.2 & 15.1 & 25.6 & 11.0 & 41.1 & 21.4 & 8.6 & 5.7 & 41.3 & 22.7 & 14.8 & 11.1 \\
\hline $50-59$ & 51.6 & 25.8 & 33.3 & 5.6 & 46.9 & 20.3 & 4.9 & 6.8 & 40.9 & 35.2 & 11.5 & 6.7 \\
\hline $60-69$ & 47.2 & 22.8 & 12.8 & 1.6 & 27.0 & 33.3 & 5.8 & 4.8 & 27.5 & 40.4 & 4.1 & 9.8 \\
\hline $70-79$ & 32.4 & 35.1 & 3.8 & 3.2 & 11.4 & 39.2 & 1.1 & 4.4 & 17.9 & 53.6 & 7.6 & 2.5 \\
\hline 80 and over & 26.8 & 46.3 & 2.1 & 6.3 & 20.0 & 23.3 & 0.0 & 0.0 & 4.2 & 58.3 & 11.1 & 0.0 \\
\hline crude rate & 45.0 & 26.4 & 17.2 & 6.3 & 31.5 & 26.5 & 7.1 & 5.5 & 30.8 & 33.9 & 10.4 & 8.5 \\
\hline adjusted rate & 50.0 & 20.8 & 21.4 & 8.0 & 34.7 & 23.4 & 7.6 & 5.5 & 31.2 & 30.5 & 10.6 & 7.7 \\
\hline $95 \% \mathrm{Cl}$ & $(49.2-50.9)$ & $(20.3-21.3)$ & $(21.0-21.9)$ & $(7.8-8.3)$ & $(34.0-35.3)(2$ & $23.0-23.9)$ & $(7.3-7.8)$ & $(5.3-5.7)$ & $(30.7-31.7)$ & $(30.0-30.9)$ & $(10.3-10.9)$ & $(7.5-7.9)$ \\
\hline testing (vs. Japan) & $p<0.01$ & $p<0.01$ & $p<0.01$ & $p=0.34$ & $p=0.55$ & $p<0.01$ & $\mathrm{p}=0.14$ & $\mathrm{p}=0.11$ & & & & \\
\hline testing (vs. inland) & $\mathrm{p}<0.01$ & $p=0.40$ & $p<0.01$ & $p=0.27$ & & & & & & & & \\
\hline
\end{tabular}

Adjusted rate was calculated using the 2012 national population. $\mathrm{Cl}$ confidence interval 
females and $11.0 \%$ for moderately dependent females, whereas that in the inland area was $4.4 \%$ and $16.1 \%$ for males and $0.6 \%$ and $3.9 \%$ for females. The figures in the coastal area were statistically higher than those in the inland area (Table 2); they were also significantly higher than those from the nationwide survey in 2013 (2.6\% and $15.3 \%$ for males, and $0.3 \%$ and $3.4 \%$ for females).

When we calculate change in smoking status between 2012 and 2014 among respondents to both surveys, respective rates of no change, improvement, and aggravation were $88.8 \%, 3.0 \%$, and $8.2 \%$ for coastal males and $94.5 \%$, $2.3 \%$, and $3.2 \%$ for coastal females, while they were $96.2 \%$, $1.3 \%$, and $2.5 \%$ for inland males and $97.4 \%, 2.0 \%$, and $0.5 \%$ for inland females. There were fewer persons with no change of smoking status in the coastal area compared with the inland area, and the rate of aggravation tended to be higher in coastal areas than in inland areas (Table 3).

When we calculate change in nicotine dependence between 2012 and 2014 in the disaster area, we see no change, improvement, and aggravation at $84.7 \%, 9.4 \%$, and $5.8 \%$ respectively for coastal males and $94.3 \%$, 3.3\%, and $2.4 \%$ for coastal females, whereas those figures are $84.8 \%, 5.7 \%$, and $9.6 \%$ for inland males and $98.5 \%, 1.0 \%$, and $0.5 \%$ for inland females. The rate of aggravation thus tended to be higher in coastal females and inland males (Table 4).

We applied multivariable analysis to examine factors associated with smoking behavior. In a statistical model explaining smoking status in 2012 (with covariates as of 2012), statistically significant risk factors for current smoking in 2012 were living in coastal area, divorce, under 9 years of education, unemployment, complete destruction of house, living in temporary housing, problem drinking (AUDIT score 12 points and over), and pathological gambling; a protective factor was professional agriculture, forestry, or fishery engagement (Table 5). The results of the multivariate analysis, which took into account the model fitness, showed that the complete destruction of houses was a significant risk factor.

In the statistical model explaining smoking status in 2014 (with covariates as of 2014), significant risk factors for current smoking were coastal area, divorce, temporary housing, and prescribed drug dependence, while a protective factor was complete destruction of house. The results of the multivariate analysis, which took into account the model fitness, showed that the coastal area, divorce, complete destruction of houses, and temporary housing were significant risk factors.

In the statistical model to explain smoking status in 2014 with covariates as of 2012, the statistically significant risk factors were coastal area, divorce, under 9 years of education, complete destruction of house, temporary housing, and problem drinking (AUDIT score 15 points and over). In the statistical model explaining aggravation of smoking status in 2014 with covariates in 2012, the no statistically significant factors were found. However, the factors costal area, divorce, losing job by the disaster, complete destruction of house, temporary housing, and loss of family member tended to be risk factors for worsening smoking status. The results of multivariate analysis with the dependent variable replaced by nicotine dependence assessed by FTND or TDS were similar to these results (supplement tables).

\section{Discussion}

This study has revealed the high smoking rate among both sexes in the tsunami disaster area after the great East Japan Earthquake and the low prevalence of male quitters in the area. The prevalence of nicotinedependent people in the area was also higher than in the inland area or in other areas of Japan. The differences in prevalence were quite large. The high smoking rate and the rate of nicotine dependence in the coastal disaster area might have already been present in this areacoastal Tohoku region. Because there were no data before the earthquake disaster, we divided data from the nationwide survey in 2013 into respondents who lived under non-coastal and coastal local governments and compared the prevalence of smoking and nicotine dependence. There was no statistically significant difference in prevalence between these two areas. This

Table 2 Nicotine dependence status by area (disaster area in 2012, all Japan in 2013)

\begin{tabular}{|c|c|c|c|c|c|c|c|c|c|c|c|c|}
\hline age group & \multicolumn{4}{|c|}{$\begin{array}{l}\text { Coastal area (Iwate and Miyagi; } n=973) \\
\text { male }(n=420) \quad \text { female }(n=553)\end{array}$} & \multicolumn{4}{|c|}{$\begin{array}{l}\text { Inland area (Iwate and Miyagi; } n=944) \\
\text { male }(n=409)\end{array}$} & $\begin{array}{l}\text { male }(n=477) \\
\text { severe }(\%) n\end{array}$ & $\begin{array}{l}\text { All Japan } \\
\text { 7) } \\
\text { moderate (\%) }\end{array}$ & $\begin{array}{l}f(n=1055) \\
\text { female }(n=5 \\
\text { severe }(\%)\end{array}$ & $\begin{array}{l}578) \\
\text { moderate (\%) }\end{array}$ \\
\hline $20-29$ & 11.8 & 29.4 & 3.8 & 19.2 & 3.3 & 23.3 & 0.0 & 8.2 & 0.0 & 11.1 & 0.0 & 7.9 \\
\hline $30-39$ & 13.0 & 30.4 & 0.0 & 17.9 & 9.3 & 18.5 & 2.5 & 7.6 & 2.7 & 21.9 & 0.0 & 1.1 \\
\hline $40-49$ & 6.0 & 38.0 & 6.2 & 8.6 & 5.6 & 20.4 & 0.0 & 7.2 & 4.1 & 16.2 & 0.9 & 1.9 \\
\hline $50-59$ & 8.6 & 34.5 & 8.5 & 15.5 & 4.8 & 19.0 & 0.0 & 0.0 & 3.5 & 23.5 & 0.0 & 3.9 \\
\hline $60-69$ & 9.6 & 26.4 & 0.8 & 8.3 & 2.8 & 14.0 & 1.0 & 3.0 & 4.6 & 13.8 & 0.8 & 3.3 \\
\hline $70-79$ & 4.7 & 21.5 & 0.0 & 2.6 & 1.4 & 4.1 & 0.0 & 0.0 & 0.0 & 8.9 & 0.0 & 1.3 \\
\hline 80 and over & 2.5 & 12.5 & 0.0 & 4.3 & 0.0 & 3.7 & 0.0 & 0.0 & 0.0 & 0.0 & 0.0 & 5.9 \\
\hline crude rate & 7.4 & 26.7 & 2.4 & 8.9 & 3.9 & 14.4 & 0.6 & 3.4 & 2.7 & 15.5 & 0.3 & 3.1 \\
\hline adjusted rate & 8.7 & 29.4 & 2.8 & 11.0 & 4.4 & 16.1 & 0.6 & 3.9 & 2.6 & 15.3 & 0.3 & 3.4 \\
\hline $95 \% \mathrm{Cl}$ & $(8.3-9.1)$ & $(28.7-30.0)$ & $(2.7-3.0)($ & $10.7-11.3)$ & $(4.2-4.7)$ & $(15.7-16.5)$ & $(0.5-0.6)$ & $(3.7-4.0)$ & $(2.4-2.7)$ & $(15.0-15.7)$ & $(0.3-0.3)$ & $(3.2-3.6)$ \\
\hline $\begin{array}{l}\text { testing (vs. Japan) } \\
\text { testing (vs. inland) }\end{array}$ & $\begin{array}{l}p<0.01 \\
p=0.01\end{array}$ & $\begin{array}{l}p<0.01 \\
p<0.01\end{array}$ & $\begin{array}{l}p<0.01 \\
p=0.01\end{array}$ & $\begin{array}{l}p<0.01 \\
p<0.01\end{array}$ & $p=0.24$ & $p=0.99$ & $p=0.52$ & $p=0.55$ & & & & \\
\hline
\end{tabular}

Adjusted rate was calculated by using 2012 national population. Nicotine dependence status was assessed by FTND. Cl confidence interval. Severe $\geq 7$ points, moderate $=4-6$ points 
Table 3 Change of smoking status from 2012 to 2014 (panel survey in disaster areas)

\begin{tabular}{|c|c|c|c|c|c|c|c|c|}
\hline & \multicolumn{4}{|c|}{$\begin{array}{l}\text { Coastal area (Iwate and Miyagi; } n=577) \\
\text { male }(n=232) \quad \text { female }(n=345)\end{array}$} & \multicolumn{4}{|c|}{$\begin{array}{l}\text { Inland area (Iwate and Miyagi; } n=353) \\
\text { male }(n=157) \quad \text { female }(n=196)\end{array}$} \\
\hline & number & $\%$ & number & $\%$ & number & $\%$ & number & $\%$ \\
\hline Smoke $\rightarrow$ Smoke & 78 & 33.6 & $\overline{44}$ & 12.8 & 49 & 31.2 & 11 & 5.6 \\
\hline NS, Quit $\rightarrow$ NS, Quit & 128 & 55.2 & 282 & 81.7 & 102 & 65.0 & 180 & 91.8 \\
\hline $\begin{array}{l}\text { Improvement } \\
\text { testing (vs inland) }\end{array}$ & 7 & $p=0.32$ & 8 & $p=1.00$ & 2 & 1.3 & 4 & 2.0 \\
\hline $\begin{array}{l}\text { Exacerbation } \\
\text { testing ( } v \text { s inland) }\end{array}$ & 19 & $\begin{array}{r}8.2 \\
p=0.03\end{array}$ & 11 & $p=0.06$ & 4 & 2.5 & $\overline{1}$ & 0.5 \\
\hline
\end{tabular}

NS non-smoker

suggests that the prevalence of smoking and nicotine dependence in the coastal area was elevated after the tsunami disaster and had not improved 3 years after the disaster. This health-related behavior may create and exacerbate future health problems in the disaster area.

Several articles on smoking behavior after disasters have been published. Smoking behavior before and after the 9/11 terrorist attacks was studied through a telephone survey, which found a higher smoking rate after the attacks [3]. In addition, low smoking cessation rate was reported among affected residents [4], rescue workers, and police officers with PTSD after the attacks [5]. It has been reported that high smoking rates and worsening of smoking status among residents are strongly related to posttraumatic stress disorder (PTSD) and major depression [16, 17].

High smoking prevalence among victims of Hurricane Katrina was also reported [6, 7]. A study on victims of Hurricane Katrina reported that PTSD and depressive symptoms are associated with smoking relapse [18]. There is a report that psychological distress after the disaster is not associated with worsening smoking behavior (increase of daily cigarette intake and nicotine dependence) [19]. In addition, the cigarette consumption was reported to increase after the Australian bushfires [8], while a follow-up study of the victims of the fireworks disaster reported that smoking became a predictor of mental disorder [20].
Previous articles related to change in smoking behaviors after an earthquake in New Zealand have been published; elevated smoking prevalence and nicotine dependence also were reported [10]. One article also claimed that there was a relationship between smoking behavior and PTSD (posttraumatic stress disorder) symptoms among Swiss victims of the Indian Ocean tsunami of 2004 [21]. As described above, there are many reports that the smoking prevalence and nicotine dependence of victims increases after natural disasters.

There are few articles reporting smoking behavior among victims by the tsunami after the great East Japan Earthquake. According to a report from Fukushima, few people started smoking after the disaster; the smoking rate was not high among victims in 2012 compared with smoking rate among the general population, and smoking rate decreased after the disaster [11]. A longitudinal study of elderly people in Iwate Prefecture from 2012 to 2015 found that smoking prevalence was higher among people with complete destroyed houses and that continued decreasing from 2011 through 2014 and increased in 2015 [22].

Although the Fukushima study was conducted on a large-scale, the response rate was low (41\%); moreover, the study was cross-sectional rather than longitudinal. The Iwate study was limited to the elderly. The strengths of the present study are that it included the coastal, tsunami-hit area; participants were randomly sampled

Table 4 Change of nicotine dependence status from 2012 to 2014 (panel survey in disaster areas)

\begin{tabular}{|c|c|c|c|c|c|c|c|c|}
\hline & \multicolumn{4}{|c|}{$\begin{array}{l}\text { Coastal area (Iwate and Miyagi; } n=556) \\
\text { male }(n=223) \quad \text { female }(n=333)\end{array}$} & \multicolumn{4}{|c|}{$\begin{array}{l}\text { Inland area (Iwate and Miyagi; } n=348) \\
\text { male }(n=157) \quad \text { female }(n=191)\end{array}$} \\
\hline & number & $\%$ & number & $\%$ & number & $\%$ & number & $\%$ \\
\hline \multirow{3}{*}{$\begin{array}{l}\text { Low } \rightarrow \text { Low } \\
\text { Moderate }+\rightarrow \text { Moderate }+ \\
\text { Improvement } \\
\text { testing (vs inland) }\end{array}$} & 141 & 63.2 & 291 & 87.4 & 118 & 75.2 & 181 & 94.8 \\
\hline & 48 & 21.5 & 23 & 6.9 & 15 & 9.6 & 7 & 3.7 \\
\hline & 21 & $\begin{array}{r}9.4 \\
p=0.32\end{array}$ & 11 & $p=1.00$ & 9 & 5.7 & 2 & 1.0 \\
\hline $\begin{array}{l}\text { Exacerbation } \\
\text { testing (vs inland) }\end{array}$ & 13 & $p=0.03$ & 8 & $\begin{array}{r}2.4 \\
p=0.06\end{array}$ & 15 & 9.6 & 1 & 0.5 \\
\hline
\end{tabular}

NS non-smoker, Moderate+ moderate or severe 
Table 5 Factors associated with smoking status in 2012, 2014, and change of the status from 2012 to 2014

\begin{tabular}{|c|c|c|c|c|c|c|c|c|c|c|c|c|c|c|}
\hline \multirow[t]{3}{*}{$\frac{d \text { dependent variable }}{\text { covariates }}$} & \multicolumn{4}{|c|}{$\begin{array}{c}\text { smokers in } 2012 \\
\text { factors in } 2012\end{array}$} & \multicolumn{4}{|c|}{$\begin{array}{l}\text { smokers in } 2014 \\
\text { factors in } 2014\end{array}$} & \multicolumn{4}{|c|}{$\frac{\text { smokers in } 2014}{\text { factors in } 2012}$} & \multicolumn{2}{|c|}{$\begin{array}{c}\text { deterioration of smoking status in } 2014 \\
\text { factors in } 2012\end{array}$} \\
\hline & \multirow{2}{*}{$\begin{array}{l}\text { smoker } \\
\text { ( } \mathrm{n}=467) \\
\text { number }\end{array}$} & \multirow{2}{*}{$\begin{array}{c}\text { non-smoker } \\
(\mathrm{n}=1511) \\
\text { number }\end{array}$} & \multicolumn{2}{|c|}{ totall $(n=1,978)$} & \multirow{2}{*}{$\begin{array}{l}\text { smoker } \\
\text { ( } \mathrm{n}=203) \\
\text { number }\end{array}$} & \multirow{2}{*}{$\begin{array}{c}\text { non-smoker } \\
(\mathrm{n}=726) \\
\text { number }\end{array}$} & \multicolumn{2}{|c|}{ total $(n=929)$} & \multirow{2}{*}{$\begin{array}{l}\text { smoker } \\
(\mathrm{n}=203) \\
\text { number }\end{array}$} & \multirow{2}{*}{$\begin{array}{c}\text { non-smoker } \\
\text { (n=726) } \\
\text { number }\end{array}$} & \multicolumn{2}{|r|}{ total $n=929$ ) } & \multicolumn{2}{|c|}{ deterioration ( $\mathrm{n}=21)$} \\
\hline & & & Odds ratio & $95 \% \mathrm{Cl}$ & & & Odds ratio & $95 \% \mathrm{Cl}$ & & & Odds ratio & $95 \% \mathrm{Cl}$ & Odds ratio & $95 \% \mathrm{Cl}$ \\
\hline costal area & 294 & 712 & 2.59 & $(2.04-3.28)$ & 137 & 440 & 1.76 & $(1.23-2.52)$ & 137 & 440 & 1.76 & $(1.23-2.52)$ & 1.81 & $(0.69-4.77)$ \\
\hline divorced & 73 & 74 & 4.20 & $(2.86-6.16)$ & 43 & 44 & 4.10 & $(2.47-6.79)$ & 39 & 40 & 4.21 & $(2.49-7.12)$ & 2.57 & $(0.35-2.37)$ \\
\hline widowed & 30 & 283 & 0.91 & $(0.66-1.27)$ & 13 & 160 & 0.89 & $(0.46-1.73)$ & 12 & 159 & 0.81 & $(0.41-1.59)$ & & \\
\hline single & 93 & 200 & 0.90 & $(0.58-1.40)$ & 31 & 83 & 0.84 & $(0.50-1.41)$ & 38 & 88 & 0.96 & $(0.59-1.56)$ & 0.62 & $(0.16-2.35)$ \\
\hline years of education $\leq 9$ & 120 & 415 & 1.60 & $(1.20-2.13)$ & 52 & 239 & 1.26 & $(0.84-1.91)$ & 54 & 234 & 1.52 & $(1.00-2.31)$ & 1.97 & $(0.67-5.83)$ \\
\hline ate & 88 & 241 & 1.29 & $(0.96-1.74)$ & 34 & 113 & 0.93 & $(0.59-1.47)$ & 34 & 96 & 1.19 & $(0.74-1.91)$ & 0.63 & $(0.17-2.27)$ \\
\hline ur & 40 & 112 & 1.57 & $(1.04-2.35)$ & 12 & 62 & 0.91 & $(0.47-1.77)$ & 23 & 73 & 1.43 & $(0.84-2.43)$ & 1.84 & $(0.52-6.53)$ \\
\hline annual income $\leq 2$ million yen & 206 & 831 & 1.16 & $(0.92-1.47)$ & 116 & 523 & 1.11 & $(0.76-1.61)$ & 98 & 426 & 1.28 & $(0.90-1.83)$ & 1.01 & $(0.41-2.51)$ \\
\hline complete destruction of house & 255 & 665 & 1.90 & $(1.51-2.39)$ & 71 & 294 & 0.66 & $(0.46-0.94)$ & 123 & 415 & 1.46 & $(1.03-2.06)$ & 2.18 & $(0.82-5.74)$ \\
\hline temporary housing & 296 & 698 & 2.73 & $(2.15-3.46)$ & 123 & 404 & 1.51 & $(1.07-2.14)$ & 137 & 435 & 1.79 & $(1.25-2.57)$ & 1.46 & $(0.57-3.69)$ \\
\hline loss of family members & 141 & 451 & 1.23 & $(0.96-1.58)$ & & & & & 63 & 275 & 0.90 & $(0.63-1.28)$ & 1.56 & $(0.64-3.81)$ \\
\hline agriculture, forestry, fishery & 13 & 79 & 0.49 & $(0.26-0.91)$ & 11 & 39 & 0.87 & $(0.42-1.81)$ & 8 & 42 & 0.62 & $(0.27-1.41)$ & & \\
\hline AUDIT 8 points ar & 98 & 121 & 1.74 & $(1.27-2.38)$ & 33 & 52 & 1.45 & $(0.88-2.40)$ & 41 & 63 & 1.52 & $(0.95-2.42)$ & 1.80 & 9) \\
\hline & 43 & 53 & 1.74 & & 16 & 27 & 1.15 & & 18 & 30 & 1.45 & $(0$. & 0.99 & $(0.12-7.91)$ \\
\hline AUDIT 15 points and over & 26 & 20 & 2.89 & $(155-5.39)$ & 7 & 13 & 0.85 & $(0.32-2.25)$ & 10 & 9 & 2.90 & (1.12-7.48) & So & \\
\hline
\end{tabular}

Results of multiple logistic regression analysis, dependent variable; current smoking. All covariates were adjusted by sex and age. Annual income means the individual income. *Statistically significant associated factors with good model fitness assessed by Homer-Lemeshow test

and included people aged 20 years and older; home visits were conducted for the survey interview; a nationwide survey was conducted for comparison; and some respondents were surveyed twice (longitudinally). Thus, this study was able to reveal changes in smoking behavior after a tsunami disaster, which worsened initially and did not improve 3 years later because of the protractedly damaged and difficult life situation that respondents were still facing due to the earthquake and tsunami. Although the results of current study are not similar to other reports from Japan, they are similar to results from other countries about smoking behavior after disasters.

There are reports that the prevalence of posttraumatic stress reaction and depressive reaction among resident survivors after the tsunami following the great East Japan Earthquake was high, and these symptoms were related to house flooding [23, 24]. There is a report that 3 years after the disaster, the depressive symptoms of survivors with loss of loved ones have recovered, but those have prolonged among survivors with property loss [25].

Therefore, it can be inferred that the high smoking rate and nicotine dependence observed in the current study have occurred through psychological distress due to damaged houses and long-term evacuation life caused by the tsunami. The smoking behavior may have been due to stress from crowding living conditions and interaction among the inhabitants of the temporary housing. Treatment for quitting thus be important for health care in temporary housing. In general, socioeconomic conditions, such as education level, income, and working conditions, are also related to smoking behavior [26, 27]. This study has revealed that the destruction of the house and subsequent temporary housing life after the disaster become important risk factors for smoking behavior even after adjusting for these socio-economic factors by multiple logistic regression analyses.

The present study has some limitations. First, the study participants did not include inhabitants of the Fukushima Prefecture. The sampling of participants from the Fukushima Prefecture was difficult because many evacuated people lived far away from their registered addresses. Second, the response rate relatively low. However, there are many inaccessible residents, and many people were exhausted from surveys by various researchers. Response rate of this survey was high one for surveys in the disaster areas because of the home visit interviews. Third, the follow-up survey was carried out only 2 years later. Since the research funds were limited, we could conduct the survey only twice. Fourth, the smoking status before the disaster is unknown; this is because survey was conducted after the disaster. We conducted a nationwide survey, excluding the three disaster prefectures, in 2013 using same survey methods and questionnaire, and compared the results with the results from the disaster areas, so that we were able to confirm that high smoking rate was a phenomenon persistent only in disaster areas.

\section{Conclusions}

As shown in this study, smoking behavior and nicotine dependence worsened among victims of the tsunami disaster after the great East Japan Earthquake and had not improved after 3 years. In particular, the smoking behavior of inhabitants living in temporary housing is serious. The findings of this study stress the importance of improvising measures for smoking control in disaster areas in the long term to reduce future health hazards.

\section{Supplementary information}

Supplementary information accompanies this paper at https://doi.org/10. 1186/s12199-020-00858-5.

\footnotetext{
Additional file 1. Table a. Propotion of nicotine dependence accessed by TSD, by area (disaster area in 2012, All Japan in 2013). Table b. Change of nicotine dependence status accessed by TSD from 2012 to 2014 (Panel survey in disaster areas). Table c. Factors associated with nicotine dependence assessed by FTND score. Table $d$. Factors associated with nicotine dependence assessed by TDS score
}

\section{Abbreviations}

Mw: Moment magnitude scale; FTND: Fagerström Test for Nicotine Dependence; TDS: Tobacco Dependence Screener; AUDIT: Alcohol Use 
Disorders Identification Test; Cl: Confidence interval; NS: Non-smoker; Moderate+: Moderate or severe; PTSD: Posttraumatic stress disorder

\section{Acknowledgements}

Authors wish to thank Shin Joho Center and investigators for conducting interview surveys in the disaster areas. We would also like to thank Editage (www.editage.jp) for English language editing.

\section{Authors' contributions}

All authors have materially participated in the research or article preparation. Authors $\mathrm{YO}$ and SM designed the study and wrote the protocol. SH, HM, RM, and $\mathrm{YM}$ conducted literature searches and provided summaries of previous studies. AK, YK, Al, and YO conducted the statistical analysis. SH, SM, AK, YK, and $Y O$ contributed in interpreting the results of the analyses. YO, SM, RM, and HM wrote the first draft of the manuscript, and all authors contributed to and have approved the final manuscript.

\section{Funding}

This work was supported by "Health and Labour Sciences Research Grants" Comprehensive Research for Persons with Disabilities [2012-2014 PsychiatryGeneral 001 (Reconstruction); Ministry of Health, Labour and Welfare, 2012]. The Ministry of Health, Labour and Welfare, Japan, had no role in the study design, collection, analysis or interpretation of the data, writing the manuscript, or the decision to submit the paper for publication.

\section{Availability of data and materials}

The datasets are not open to the public. Since all analyzes have not been completed, the consent from the members of this research group cannot be obtained.

\section{Ethics approval and consent to participate}

The study and surveys were approved by the institutional ethical committee of Kurihama Medical and Addiction Center (\#2012181). This study was carried out in accordance with the Declaration of Helsinki. The interview survey was conducted for those who gave consent after explaining the purpose of the survey.

\section{Consent for publication}

Not applicable.

\section{Competing interests}

The authors declare that they have no competing interests.

\section{Author details}

'Division of Environmental and Preventive Medicine, Department of Social Medicine, Faculty of Medicine, Tottori University, 86 Nishi-cho, Yonago, Tottori 683-8503, Japan. ${ }^{2}$ National Hospital Organization Kurihama Medical and Addiction Center, 5-3-1 Nobi, Yokosuka, Kanagawa 239-0841, Japan. ${ }^{3}$ Department of Pediatrics, Tottori University Hospital, 36-1 Nishi-cho, Yonago, Tottori 683-8504, Japan.

Received: 12 February 2020 Accepted: 1 June 2020

\section{Published online: 11 June 2020}

\section{References}

1. National Police Agency of Japan. Damage situation and police countermeasures by the 2011 Earthquake off the Pacific coast of Töhoku, 8 March 2019. https://wnw. npa.go.jp/news/other/earthquake2011/pdf/higaijokyo.pdf. Accessed 1 Apr 2019.

2. Reconstruction Agency of Japan. The number of the refugees. 2019. http:// www.reconstruction.go.jp/topics/main-cat2/sub-cat2-1/20190227_hinansha. pdf. Accessed 1 Apr 2019.

3. Vlahov D, Galea S, Ahern J, Resnick H, Boscarino JA, Gold J, et al. Consumption of cigarettes, alcohol, and marijuana among new York City residents six months after the September 11 terrorist attacks. Am J Drug Alcohol Abuse. 2004;30(2):385-407.

4. Welch AE, Jasek JP, Caramanica K, Chiles MC, Johns M. Cigarette smoking and 9/11-related posttraumatic stress disorder among world trade center health registry enrollees, 2003-12. Prev Med. 2015;73:94-9.

5. Zvolensky MJ, Farris SG, Kotov R, Schechter CB, Bromet E, Gonzalez A, et al. Posttraumatic stress symptoms and smoking among world trade center disaster responders: a longitudinal investigation. Compr Psychiatry. 2015;63:46-54.
6. Beaudoin CE. Hurricane Katrina: addictive behavior trends and predictors. Public Health Rep. 2011;126(3):400-9.

7. Flory K, Hankin BL, Kloos B, Cheely C, Turecki G. Alcohol and cigarette use and misuse among hurricane Katrina survivors: psychosocial risk and protective factors. Subst Use Misuse. 2009;44(12):1711-24.

8. Parslow RA, Jorm AF. Tobacco use after experiencing a major natural disaster: analysis of a longitudinal study of 2063 young adults. Addiction. 2006;101(7):1044-50.

9. Van der Velden PG, Grievink L, Olff M, Gersons BP, Kleber RJ. Dutch Ministry of Health, welfare, and sport. Smoking as a risk factor for mental health disturbances after a disaster: a prospective comparative study. J Clin Psychiatry. 2007:68(1):87-92.

10. Erskine N, Daley V, Stevenson S, Rhodes B, Beckert L. Smoking prevalence increases following Canterbury earthquakes. Sci World J. 2013;596957. https://doi.org/10.1155/2013/596957 eCollection 2013.

11. Nakano H, Ohira T, Maeda M, Yabe H, Ohtsuru A, Suzuki Y, et al. Associations of disaster-related and psychosocial factors with changes in smoking status after a disaster: a cross-sectional survey after the great East Japan earthquake. BMJ Open. 2018;8(6):e018943. https://doi.org/10.1136/ bmjopen-2017-018943.

12. Heatherton TF, Kozlowski LT, Frecker RC, Fagerström KO. The Fagerström test for nicotine dependence: a revision of the Fagerström tolerance questionnaire. Br J Addict. 1991;86(9):1119-27.

13. Kawakami N, Takatsuka N, Inaba S, Shimizu H. Development of a screening questionnaire for tobacco/nicotine dependence according to ICD-10, DSMIII-R and DSM-IV. Addict Behav. 1999;24(2):155-66.

14. Babor TF, de la Fuente JR, Saunders J, Grant M. AUDIT the alcohol use disorders identification test: guidelines for use in primary health care. WHO/ MNH/DAT 89.4. Geneva: World Health Organization; 1989.

15. Hiro H. WHO/AUDIT the alcohol use disorders identification test: Japanese version. Tokyo: Chiba Test Center; 2000.

16. Nandi A, Galea S, Ahern J, Vlahov D. Probable cigarette dependence, PTSD, and depression after an urban disaster: results from a population survey of new York City residents 4 months after September 11, 2001. Psychiatry. 2005;68(4):299-310.

17. Pfefferbaum B, North CS, Pfefferbaum RL, Christiansen EH, Schorr JK, Vincent RD, et al. Change in smoking and drinking after September 11, 2001, in a national sample of ever smokers and ever drinkers. J Nerv Ment Dis. 2008;196(2):113-21.

18. Alexander AC, Ward KD, Forde DR, Stockton M. Are posttraumatic stress and depressive symptoms pathways to smoking relapse after a natural disaseter? Drug Alcohol Depend. 2019;195:178-15.

19. Alexander AC, Ward KD, Forde DR, Stockton M, Read MC. Do current smokers use more cigarettes and become more dependent on nicotine because of psychological distress after a natural disaster? Addict Behav. 2019;93:129-34.

20. Fergusson DM, Horwood $\sqcup$, Boden JM, Mulder RT. Impact of a major disaster on the mental health of a well-studied cohort. JAMA Psychiatry. 2014;71(9):1025-31.

21. Vetter S, Rossegger A, Rossler W, Bisson Jl, Endrass J. Exposure to the tsunami disaster, PTSD symptoms and increased substance use - an internet based survey of male and female residents of Switzerland. BMC Public Health. 2008;8:92. https://doi.org/10.1186/1471-2458-8-92.

22. Tsubota-Utsugi M, Yonekura Y, Tanno K, Nozue M, Shimoda H, Nishi N, et al. Association between health risks and frailty in relation to the degree of housing damage among elderly survivors of the great East Japan earthquake. BMC Geriatr. 2018;18(1):133. https://doi.org/10.1186/s12877-018-0828-X.

23. Matsubara C, Murakami H, Imai K, Mizoue T, Akashi H, Miyoshi C, et al. Prevalence and risk factors for depressive reaction among resident survivors after the tsunami following the great East Japan earthquake, march 11, 2011. PLoS One. 2014;9(10): e109240. https://doi.org/10.1371/journal.pone.0109240 eCollection 2014.

24. Matsubara C, Murakami H, Imai K, Mizoue T, Akashi H, Miyoshi C, et al. Prevalence and risk factors for post-traumatic stress reaction among resident survivors of the tsunami that followed the great East Japan earthquake, march 11, 2011. Disaster Med Public Health Prep. 2016;10(5):746-53.

25. Tsuboya T, Aida J, Hikichi H, Subramanian SV, Kondo K, Osaka K, et al. Predictors of depressive symptoms following the great East Japan earthquake: a prospective study. Soc Sci Med. 2016;161:47-54.

26. De Vogli R, Santinello M. Unemployment and smoking: does psychosocial stress matter? Tob Control. 2005;14(6):389-95.

27. Hiscock R, Bauld L, Amos A, Fidler JA, Munafò M. Socioeconomic status and smoking: a review. Ann N Y Acad Sci. 2012;1248:107-23.

\section{Publisher's Note}

Springer Nature remains neutral with regard to jurisdictional claims in published maps and institutional affiliations. 